\title{
Changes of Tropical Cyclone Size in three Oceanic Basins of the Northern Hemisphere since 2001
}

\author{
Author1Banglin Author1Zhang \\ NOAA NCEP Environmental Modeling Center, College Park, MD 20740, \\ USA \\ Author2Jason Author2A. Author2Sippel \\ NOAA AOML/Hurricane Research Division, Miami, FL 33149, USA \\ Author3Julian Author3X.L. Author3Wang \\ NOAA/Air Resources Laboratory, College Park, MD 20740, USA
Author4Vijay Author4Tallapragada
NOAA NCEP Environmental Modeling Center, College Park, MD 20740, USA \\ Author5Zaizhong Author5Ma
}

NOAA NCEP Environmental Modeling Center, College Park, MD 20740, USA

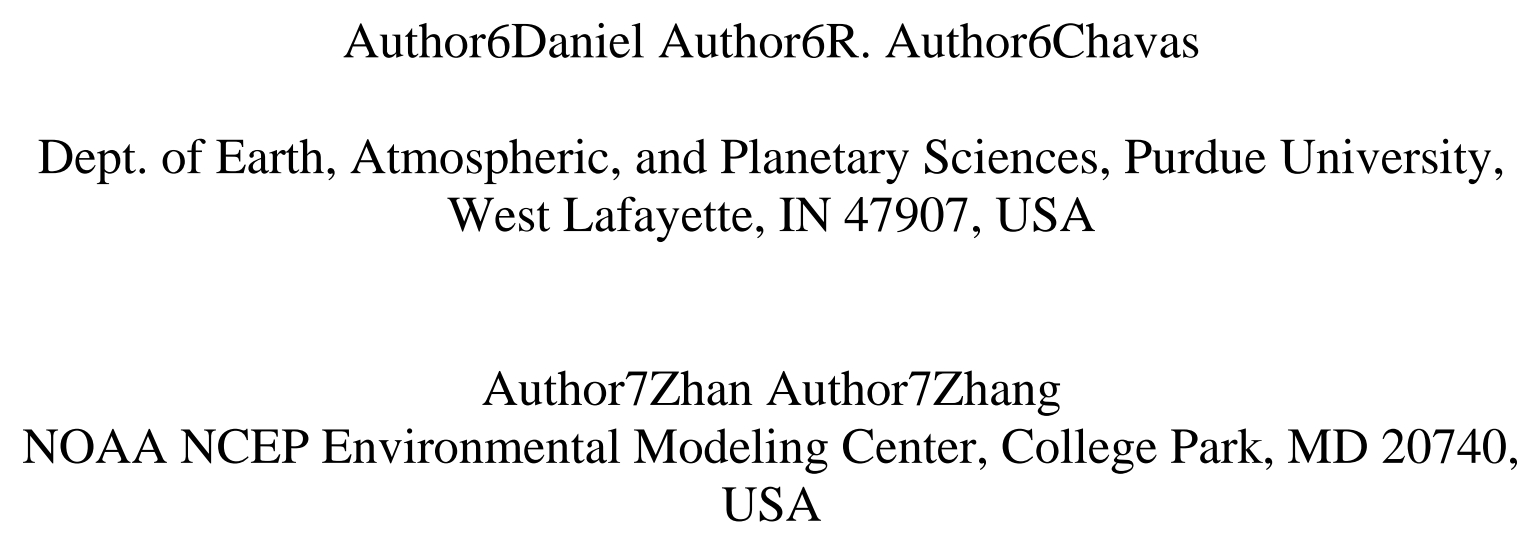

Author7Zhan Author7Zhang

NOAA NCEP Environmental Modeling Center, College Park, MD 20740, USA 
Author8Qingfu Author8Liu

38 NOAA NCEP Environmental Modeling Center, College Park, MD 20740, USA

40

41

42

43

44

45

46

47

48

49

50

51

52

53

54

55

56

57

58

59

60

61

62

63

64

65

66

67

68

69

70

Corresponding author address: Banglin Zhang, NOAA NCEP Environmental Modeling Center, College Park, MD 20740, USA.

E-mail: Banglin.Zhang@noaa.gov

NOAA NCEP Environmental Modeling Center, College Park, MD 20740, USA

71 
88 from the 16-year best track data. The relationships between storm size and sea surface

89 temperature anomaly and the departure from the zonal mean have also been investigated,

90 and some statistically significant correlations are found. 


\section{1. Introduction}

93 Tropical cyclones are a major source of natural catastrophic losses worldwide. It

94 is estimated that 10,000 people have died every year since 1980 due to tropical cyclones

95 (Doocy et al. 2013), and thus it is of great importance to study tropical cyclones and to

96 understand their response to changes in environmental conditions such as sea surface

97 temperature (SST). The sensitivity of frequency, intensity, and duration of tropical

98 cyclones to climate change has been extensively investigated with a general conclusion

99 that both global and regional changes in TC behavior should be expected as the climate

100 and SST change (e.g., Emanuel et al 2008, Kossin 2017).

101 Though numerous studies have examined the complex response of tropical

102 cyclone frequency and intensity to climate change (Emanuel 2005; Webster et al, 2005;

103 Shen 2006; Emanuel et al. 2008; Barbosa 2011; Emanuel and Sobel, 2013; Mei et al.

104 2015; Kossin, 2017); uniform conclusions have not been reached regarding recent global

105 intensity trends. For example, Webster et al (2005) found that both the number and

106 percentage of global category 4-5 hurricanes increased significantly from 1970 to 2004.

107 Meanwhile, looking at the 1986-2005 period, Klotzbach (2006) found that the trend of

108 global accumulated cyclone energy (ACE) index and global category $4-5$ hurricanes was

109 not significant despite warming SSTs. Likewise, Klotzbach and Landsea (2015)

110 examined the period between 1990 and 2014 and found an insignificant downward trend

111 in global frequency of category 4-5 hurricanes (encompassing an upward trend up to

112 2004, and then a downward trend thereafter). The same study found the percentage of

113 category 4 and 5 hurricanes showed an insignificant upward trend and significant

114 downward trend in ACE. 
115 Other studies have examined the "storm days" parameter", generally finding

116 significant interdecadal variability. Landsea et al (1999) was one of earliest studies to

117 note this, and for the period for 1944-1996 they found a greater degree of statistical

118 significance in storm days than in hurricane frequency. With updated data, Webster et al

119 (2005) found no significant linear trends in storm days from 1970 to 2004, though they

120 did find a significant decadal-scale oscillation. Wang et al (2010) similarly found a

121 large-amplitude fluctuation in storm days from 1965-2008 that was regulated by El

122 Niño/Southern Oscillation (ENSO) and the Pacific Decadal Oscillation (PDO). Like

123 previous studies, they did not find a linear trend, suggesting that the rising temperature so

124 far has not yet had an impact on the global total number of storm days.

125 A number of studies have also uncovered regional relationships between SST and

126 TC trends. For example, Klotzbach (2006) found a statistically significant relationship

127 between SSTs and both ACE and category 4 -5 hurricane frequency in both the North

128 Atlantic (NATL) and the Eastern North Pacific (EPAC). Similarly, Martinez-Sanchez

129 and Cavazos (2014) examined the EPAC main development region (MDR) from 1970-

1302010 and found a statistically significant SST increase, an insignificant trend in category

131 4-5 hurricanes, and a significant decrease in the frequency of all hurricanes. The

132 hurricane trend in the EPAC MDR appears to be linked to the PDO, and the frequency

133 category 4-5 hurricanes in that basin is significantly related to both the PDO and ENSO.

134 In a different study, Jin et al. (2014) uncovered an oceanic pathway that brings El Niño's

135 heat into the Northeastern Pacific basin to directly fuel intense hurricanes in that basin

136 two or three seasons after its winter peak. Finally, Mei et al (2015) found that upper

\footnotetext{
${ }^{1}$ This parameter counts the number of days in a season that a tropical cyclone exists. If multiple storms coexist, then they both individually contribute to the total.
} 
137 oceanic temperatures in the central and western Pacific control the rate and duration of

138 typhoon intensification, and recent anomalous warming has led to unprecedentedly high

139 average typhoon intensity during the global warming hiatus period.

140 In this report we focus on changes in storm size and its relationship with SST, a

141 relatively understudied topic. A major motivation for this work is that storm size can

142 significantly impact damage, particularly that caused by storm surge (e.g., Irish et al.

143 2008). Another motivation is that storm size impacts predictability; large storms tend to

144 evolve more slowly and are more predictable than small storms (Carrasco et al. 2014).

145 Among the very little work that has related storm size and SST, Lin et. al (2015) suggest

146 that TC size is more strongly related to the departure of local SST from area mean than it

147 is to the SST anomaly from temporal average (SSTA). Therefore, this study examines

148 trends in storm size and relates those trends to both the departure of local SST from the

149 latitudinal mean (SSTD) and SSTA.

150 Though few have examined the relationship between SST and storm size, a

151 number of previous studies have investigated the climatology of storm size. For example,

152 the radius of the outermost closed isobar (ROCI) was used to examine the climatology

153 and structure of tropical cyclones of different sizes (Merrill, 1984). A climatology with

154 multiple tropical cyclone size parameters for the North Atlantic basin was then

155 established with data from 1988 through 2002 (Kimball and Mulekar, 2004). Recently the

156 Quick Scatterometer (QuikSCAT) surface wind speed estimates and storm-centered

157 infrared data were also used to estimate the climatology of storm size (Chavas and

158 Emanuel, 2010; Knaff et al. 2014; Chan and Chan; 2015). However, observed trends in

159 storm size parameters such as the radius of maximum wind (RMW) and the average 
160 radius of 34-kt wind (AR34) have not been extensively examined due to the limited

161 sampling size and data availability.

162 The remainder of this study proceeds as follows. The size data and the analytic

163 method for diagnosing the trend and changes of storm size are described in section data

164 and methods. The results are present in section results, and the section summary and

165 discussions summarize the findings and present some discussions.

166

167 2. Data and methods

168 This research makes use of a variety of data sources to give as complete a picture

169 as possible of how hurricane size has evolved over the past 40 years. For years from

1702004 onward, the best-track (i.e., b-decks) datasets are used from the National Hurricane

171 Center (NHC) for the NATL and EPAC and from the Joint Typhoon Warning Center

172 (JTWC) for the WPAC. As of the time of this research, post-season quality control (QC)

173 had been applied to the NATL and EPAC data through 2015 and to Western North

174 Pacific (WPAC) data through 2014. Thus, the very latest b-deck data is "real-time" and

175 has not undergone the same rigorous QC as the slightly older data. For years before

176 2004, the best-track data does not include size information, so we have turned to the

177 extended best track (EBT) dataset ${ }^{2}$, as described in Demuth et al. (2006), for the size data

178 over the NATL and EPAC basins. Finally, the best track cyclone data ${ }^{3}$ from Japan

179 Meteorological Agency (JMA) RSMC Tokyo - Typhoon Center were also used for

180 comparison (Kishimoto 2008) over the WPAC.

\footnotetext{
${ }^{2}$ http://rammb.cira.colostate.edu/research/tropical_cyclones/tc_extended_best_track_data $\underline{\text { set }}$

${ }^{3}$ http://www.jma.go.jp/jma/jma-eng/jma-center/rsmc-hp-pub-eg/besttrack.htm
} 
The EBT dataset uses the NHC best-track postanalysis when possible, but

182 operational size estimates are used for earlier storms. There are some inconsistencies

183 between the EBT dataset and the b-decks for post-2004 storms, so we have chosen to use

184 the b-decks instead of EBT for this time period. The best-track b-deck data contain

185 careful estimates of TC position, intensity and size (Demuth et al 2006; Landsea et al.

186 2010; Landsea and Franklin 2013). The size parameters include the RMW and the 34-,

187 50- and $64 \mathrm{kt}$ wind radii (R34, R50, and R64, respectively), but as mentioned above this

188 information has only been included in best-track archives since 2004. The operational

189 size estimates available before 2004 (NATL: 1988-2003; EPAC: 2001-2003) have not

190 undergone the same level of quality control as those in the best-track archives.

191 For the purpose of this study, we examine trends of RMW and the four-quadrant

192 average of R34 (hereafter AR34) from the extended best track dataset, where one or more

193 of the quadrants with 0 value are not included in the average. The RMW gives a sense of

194 the compactness of the inner core, whereas AR34 demonstrates the breadth of the wind

195 field. The JMA dataset covers the period from 1951 to 2016, but size parameters are not

196 available until 1977. One set of parameters are the longest and shortest radii of 50kt

197 winds or greater (R50 $\mathrm{L}$ and R50s), and another set of parameters are the longest and

198 shortest radii of $30 \mathrm{kt}$ winds or greater $\left(\mathrm{R} 30_{\mathrm{L}}\right.$ and $\left.\mathrm{R} 30_{\mathrm{S}}\right)$. Using this data, we define $50=$

$199 \sqrt[2]{R 50_{L} \times R 50_{S}}$, and $R 30=\sqrt[2]{R 30_{L} \times R 30_{S}}$ as the area-conserving mean radii for 50kt 200 and 30kt winds.

201 For all data sources, linear and quadratic curves (McDonald 2014) are fit to the 202 time series with the linear equation

$$
Y=a X+b
$$


204 and the quadratic equation

$$
Y=a X^{2}+b X+c .
$$

206 Here $\mathrm{X}$ is time in yearly index. A P-value test is used to check if the trends of storm size

207 are statistically significant. Trends are examined separately for hurricanes/typhoons

208 (HT), tropical storms (TS), and all storms with Vmax > $34 \mathrm{kt}$ (ALL) according to the

209 storm intensity at each analysis time.

210 To study the relationship between storm size and sea surface temperature, the

211 Extended Reconstructed SST (ERSST) v3b data (Smith et al. 2008; L'Heureux et al.

212 2013; Huang et al. 2015) are used to calculate the sea surface temperature anomalies

213 (SSTA) and the departure of the local sea-surface temperature from the zonal mean

214 (SSTD). Point values of SSTA (computed from a monthly average with respect to

215 monthly averages from January 1977 to December 2015), and SSTD are then calculated

216 according to the best-track position. The collocated SSTA and SSTD yield the annual

217 time series for each storm category, and correlation is calculated between storm size and 218 SSTA/SSTD.

\section{3. Results}

220 This section examines the characteristics and trends in storm size, collectively in 221 the NATL, EPAC, and WPAC, and also individually in each basin. The initial focus is 222 on 2001-2016, which corresponds to the period when size information is available for all

223 three basins. Longer-term NATL and WPAC datasets are then interrogated to show

224 trends in individual basins within a larger context. Emphasis is placed on results that are

225 statistically significant with $90 \%$ confidence based on both linear and quadratic fitting 
226 significance tests, as indicated in Tables 1-7. The changes in size are then related to SST

227 changes (Tables 8-12). As a first step, in order to facilitate comparison of our dataset

228 with those of previous studies, trends in storm days are also examined.

229 a) Storm days

230 SD is shown in Fig. 1c as an average over the three basins studied and in Fig. 2

231 for the individual basins. For the three-basin average, none of the SD trends are

232 statistically significant, which agrees with previous published work. Meanwhile, the per-

233 basin results in Fig. 2 reveal the unique characteristics of each basin. The WPAC has the

234 highest percentage of strong storms, as indicated by the fact that HT storm days are

235 almost equal to those of TS. In addition, the WPAC has the most total storm days for

236 ALL storms. The only basin with statistically significant SD trends is the EPAC, where

237 the positive trend of all three categories is significant. A possible reason for this unique

238 EPAC characteristic will be discussed later.

239 b) Basic size characteristics and linear trends

240 In Fig. 1 we first examine extended best-track trends averaged over all three

241 examined basins. The general characteristics of the data, with HT having much larger

242 AR34 and much smaller RMW, are consistent with the knowledge that mature storms are

243 larger but have more compact inner cores (Shen, 2006). With regard to the trends, the

244 general picture painted by Fig. 1 is a tendency for decreasing AR34 driven mostly by

245 hurricanes and typhoons. The AR34 trends for HT and ALL, which are statistically

246 significant, are respectively -15.0 and $-7.77 \mathrm{NMi} /$ decade. The significant trends of RMW,

247 on the other hand, are driven by TS. RMW trends in TS and ALL, both of which are

248 significant, are respectively 4.49 and 3.16 NMi/decade. 
Figures 3-4 demonstrate a great deal of inter-basin variability in the above results.

250 The RMW, for example, has generally been much larger in the NATL than in the WPAC

251 and EPAC (Fig. 3). Meanwhile, AR34 in the EPAC tends to be smaller than that in the

252 NATL and WPAC (Fig. 4). As for the trends, RMW of TS has increased all three basins,

253 though the trend for HT varies by basin (Fig. 3), and RMW trends are significant only in

254 the NATL and EPAC. In the NATL the inner core size has increased for all three

255 categories, though the increase is not significant for HT. In the EPAC, the RMW trends

256 for HT and TS oppose each other, and only the HT trend is significant. The increasing

257 RMW for WPAC TS is also very close to being significant. Meanwhile, the trends of

258 AR34 are negative for HT in all three basins, but for TS the trends vary by basin. Despite

259 the significant negative HT trend in global AR34, only the HT trend in the EPAC is

260 significant.

261 c) Quadratic trends

262 In addition to linear trends, we have examined quadratic trends, which might

263 better highlight decade-scale forcing in the individual basins. The quadratic fitting for all

264 parameters shows a large increase in statistical significance in both East and West Pacific

265 basins, but not in the Atlantic. In fact, in the EPAC, all parameters have a significant

266 quadratic trend. This is likely indicative of the more pronounced decadal forcing (perhaps

267 of SST) in the Pacific basins than in the Atlantic for the period covered.

268 d) Trends in extended datasets

269 This subsection examines longer-term NATL (Fig. 5) and WPAC (Fig.6) datasets

270 to show how the above trends fit within a larger context. In the NATL the period

271 examined is from 1988 to 2015 , which covers the availability of EBT data. In the 
272 WPAC, a 40-year dataset of R30 and R50 was calculated from data provided by JMA

273 RSMC Tokyo - Typhoon Center.

274 Since the alternative WPAC dataset is based off of fundamentally different data

275 from an independent source, it is wise to assess how well it corresponds with the EBT

276 and b-deck data during the period of overlap. As such, we have computed the correlation

277 coefficient between R30 from Fig. 6 and AR34 from Fig. 4b for the period of overlap.

278 The correlation for TS, HT, and ALL is respectively 0.56, 0.73, and 0.62. All of these

279 values are statistically significant with at least $95 \%$ confidence.

280 The extended NATL dataset in Fig. 5 exhibits both similarities and differences

281 when compared against more recent data. Both datasets exhibit a significant increase in

282 RMW for TS and ALL, though a significantly negative linear trend in RMW is seen in

283 the extended data set but not the more recent data for HT. However, we consider this

284 trend to be suspicious because it appears to reflect a sudden change centered around the

285 year 2001; before that the RMW was relatively constant near $30 \mathrm{~nm}$, and after that it was

286 relatively constant around $20 \mathrm{~nm}$. Thus, this could reflect a change in measurement

287 method or instrument availability. The linear trends of AR34 and SD for TS are also

288 significant in the extended dataset but not in the recent data. In addition, quadratic fits to

289 the extended NATL dataset exhibit much higher significance than do the quadratic fits to

290 the shorter 2001-2016 data. This suggests that the extended dataset better captures

291 decade-scale forcing in the NATL than does the more recent data.

292 The major difference between the extended and recent WPAC datasets is that a

293 number of the linear trends are significant in the extended dataset. In particular, HT has

294 exhibited a significant negative linear trend in both AR50 and AR30 since 1977. These 
295 trends are consistent with the negative linear trends of RMW and R34 for WPAC HT

296 since 2002, though the recent trends do not carry statistical significance.

297 e) Relationship with SSTA and SSTD

298 This section explores the relationship between storm size and SD with

299 SSTA/SSTD. In general, there are only two or possibly three meaningful, consistent

300 relationships amongst the basins. Some of the correlations that are statistically

301 significant (e.g., Tables 8 \& 11) are sufficiently weak that they are not particularly

302 meaningful. In other instances they are sporadic significant correlations for one time

303 series in a basin but not the other (c.f., Tables 9 and 10 with Table 11 for NATL).

304 In the WPAC, SD is significantly anticorrelated with both SSTA and SSTD in

305 both the JMA and JTWC data sets (Tables 9, 10, and 12). The correlation is significant

306 with all storm categories for JMA and SSTD. However, for JMA with SSTA as well as

307 for JTWC with both SSTA and SSTD, the correlation is significant for only TS and ALL.

308 Despite the statistical significance, the correlation values are generally below 0.3 in the

309 JMA dataset, suggesting at most 10\% of the variance in SD can be explained by SST

310 variations. However, in the shorter JTWC dataset the correlations are considerably larger

311 such that up to $35 \%$ of the variance in SD can be explained by SST variations.

312 There is also some suggestion of a negative relationship between storm size and

313 SSTA/SSTD in the WPAC. This significant anticorrelation only shows up in the JMA

314 dataset (Table 12), where it is present for all storm classes with SSTD and for TS and

315 ALL with SSTA. The correlation is strongest for SSTD, where SST variations explain up 316 to $25 \%$ of the variance in AR30. 
There is also a rather strong relationship between SST and storm behavior in the

318 EPAC. For all three storm categories SD is positively related to SSTA. The correlation

319 magnitudes are the largest for all datasets, suggesting that EPAC SSTA contributes to as

320 much as $50 \%$ of SD variability in that basin (Table 9). This is perhaps the most

321 significant finding of this study and warrants some further analysis. Turning back to Fig.

322 2, recall that there has been a rather large increase in SD over the course of the EPAC

323 dataset (since 2001). Commensurate with this increase, Fig. 7 shows that there has been

324 a substantial increase in SST over most of the EPAC during this same time. This is

325 notably different than in other basins, where SST has regions of both positive and

326 negative trends. Thus, it appears that a positive local trend in EPAC SST has been

327 causing an increase in SD in that basin.

329 4. Discussions

$330 \quad$ Storm size parameters play a very important role in cyclone forecasts, storm

331 surge studies, and the cyclone climate and its changes (Rotunno and Emanuel, 1987; Irish

332 et al. 2008; Chen et al. 2011; Emanuel 2012; Stern et al. 2015; Xu et al. 2016). We used

333 linear and quadratic curve fittings to investigate the recent trends of cyclone size RMW

334 and AR34 as well as storm duration index and found that (1) RMW for TS increases in

335 all three basins; (2) for stronger HT storms, RMW increases in the NATL basin, but

336 decreases in the WPAC and EPAC basins. (3) AR34 trends for HT storms are negative in

337 all three basins, but positive for TS storms in both NATL and WPAC and negative in

338 EPAC. (4) The storm duration index SD increases over time for all categories of storms 
339 in NATL, but decreases for all categories in EPAC. (5) In WPAC the SD trend for TS is

340 positive while negative for HT storms.

341 The statistical significances of two storm size parameters RMW and AR34 are

342 quite different, with RMW having more significant trends than AR34. This could suggest

343 AR34 being influenced more by environmental conditions, thus having more complex

344 characteristics. The parameter RWM is more representative of storm size reflecting

345 forcing strength, such as SST, with a better linear trend and decadal scale variability. The

346 quadratic fitting also increases the confidence level of statistical significance, particularly

347 in the WPAC and EPAC basins where the decadal scale variability accounts for a

348 significant part of the size variation.

350 Acknowledgments.

351 NOAA_ERSST_V3b were provided by the NOAA/OAR/ESRL PSD, Boulder, Colorado,

352 USA, from their website at http://www.esrl.noaa.gov/psd/. The 16 year best track data

353 for the NATL, WPAC, and EPAC basins were downloaded from NOAA/NHC at

354 http://ftp.nhc.noaa.gov/atcf/ and the US Navy/JTWC at

355 http://www.usno.navy.mil/NOOC/nmfc-ph/RSS/jtwc/best_tracks/wpindex.php. The 40

356 year WPAC best track data were provided by JMA RSMC Tokyo - Typhoon Center at

357 the website http://www.jma.go.jp/jma/jma-eng/jma-center/rsmc-hp-pub-eg/besttrack.htm.

358 The extended best track data for the NATL and EPAC basins were downloaded

359 http://rammb.cira.colostate.edu/research/tropical_cyclones/tc_extended_best_track_datas

360 et. We thank the HWRF team of NOAA/NCEP/EMC for making this study possible. This

361 study was supported by US NOAA HFIP Project. 
362

363 


\section{References}

365 Barbosa, S.M., 2011: Testing for deterministic trends in global sea surface temperature.

366 Journal of Climate, 24(10), pp.2516-2522.

367 Bell G. D., et al., 2000: Climate assessment for 1999. Bull. Am. Meteorol. Soc. 81, s1368 s50.

369 Carrasco, C., C. Landsea, and Y. Lin, 2014: The influence of tropical cyclone size on its

370 intensification. Wea. Forecasting, 29, 582-590, doi:10.1175/WAF-D-13-00092.1.

371 Chan, K. T. E., and J. C. L. Chan, 2015: Global climatology of tropical cyclone size as

372 inferred from QuikSCAT data. Int. J. Climatol., 35: 4843-4848. doi:10.1002/joc.4307.

373 Chavas, D.R., and K. A. Emanuel, 2010: A QuikSCAT climatology of tropical cyclone

374 size. Geophys. Res. Lett. 37, L18816.

375 Chen, D. Y. -C., K. K. W. Cheung, and C. -S. Lee, 2011: Some implications of core

376 regime wind structures in western North Pacific tropical cyclones. Wea. Forecasting, 26,

377 61-75, doi:10.1175/ 2010WAF2222420.1.

378 Demuth, J., M. DeMaria, J.A. Knaff, 2006: Improvement of advanced microwave

379 sounder unit tropical cyclone intensity and size estimation algorithms. J. Appl. Meteor., $380 \quad 45,1573-1586$.

381 Doocy, S., A. Dick, A. Daniels, and T.D. Kirsch, 2013: The Human Impact of Tropical

382 Cyclones: a Historical Review of Events 1980-2009 and Systematic Literature Review.

383 PLOS Currents Disasters. Apr 16, 2013.

384 Emanuel, K. A., 1989: The finite-amplitude nature of tropical cyclogenesis. J. Atmos.

385 Sci., 46, 3431-3456, doi:10.1175/ 1520-0469(1989)046,3431:TFANOT.2.0.CO;2. 
386 Emanuel, K. A., 2005: Increasing destructiveness of tropical cyclones over the past 30

387 years. Nature 436, 686-688.

388 Emanuel, K. A., 2012: Self-stratification of tropical cyclone outflow. Part II: Implications

389 for storm intensification. Journal of the Atmospheric Sciences, 69(3), pp.988-996.

390 Emanuel, K.A., and A. Sobel, 2013: Response of tropical sea surface temperature,

391 precipitation, and tropical cyclone-related variables to changes in global and local

392 forcing. J. Adv. Model. Earth Syst., 5, 447-458, doi:10.1002/jame.20032.

393 Emanuel, K.A., R. Sundararajan, and J. Williams, 2008: Hurricanes and global warming:

394 Results from downscaling IPCC AR4 simulations. Bull. Amer. Meteor. Soc., 89, 347-

395 367, doi:10.1175/BAMS-89-3-347.

396 Huang, B., V. F. Banzon, E. Freeman, J. Lawrimore, W. Liu, T. C. Peterson, T.M. Smith,

397 P. W. Thorne, S. D. Woodruff, and H. M. Zhang, 2015: Extended reconstructed sea

398 surface temperature version 4 (ERSST. v4). Part I: Upgrades and intercomparisons.

399 Journal of climate, 28(3), pp.911-930.

400 Irish, J. L., D. T. Resio, and J. J. Ratcliff, 2008: The influence of storm size on hurricane

401 surge. J Phys. Oceanogr. 38:2003-2013.

402 Jin, F.,F., J. Boucharel, and I. I. Lin, 2014: Eastern Pacific tropical cyclones intensified

403 by El Niño delivery of subsurface ocean heat. Nature, 516(7529), pp.82-85.

404 Kimball, S.K., and M. S. Mulekar, 2004: A15-year climatology of North Atlantic tropical

405 cyclones. Part I: Size parameters. J.Climate, 17, 3555-3575, doi:10.1175/1520-

406 0442(2004)017,3555: AYCONA.2.0.CO;2. 
407 Kishimoto, K. (2008), Revision of JMA's early stage Dvorak analysis and its use to

408 analyze tropical cyclones in the early developing stage, RSMC Tokyo-Typhoon Center

409 Technical Review, 10, pp.1-12.

410 Klotzbach, P.J., 2006: Trends in global tropical cyclone activity over the past twenty

411 years (1986-2005), Geophys. Res. Lett., 33, L10805, doi:10.1029/ 2006GL025881.

412 Klotzbach, P. J., and C. W. Landsea, 2015: Extremely intense hurricanes: Revisiting

413 Webster et al. (2005) after 10 years. J. Clim. 28:7621-7629.

414 Knaff, J.A., S. P. Longmore, and D. A. Molenar, 2014: An objective satellite-based

415 tropical cyclone size climatology. J. Climate, 27, 455-476.

416 Kossin, J.P., 2017: Hurricane intensification along United States coast suppressed during

417 active hurricane periods. Nature.

418 Landsea, C. W., and J. L. Franklin, 2013: Atlantic hurricane database uncertainty and

419 presentation of a new database format. Mon. Wea. Rev., 141, 3576-3592,

420 doi:10.1175/MWR-D-12-00254.1.

421 Landsea, C.W., G. A. Vecchi, L. Bengtsson, and T. R. Knutson, 2010: Impact of duration

422 thresholds on Atlantic tropical cyclone counts. J. Climate, 23, 2508-2519.

423 L'Heureux, M.L., D. C. Collins, and Z. -Z. Hu, 2013: Linear trends in sea surface

424 temperature of the tropical Pacific Ocean and implications for the El Niño-Southern

425 Oscillation. Climate Dyn., 40, 1223-1236, doi:10.1007/s00382-012-1331-2.

426 Lin, Y, M. Zhao, and M. Zhang, 2015: Tropical cyclone rainfall area controlled by

427 relative sea surface temperature. Nat. Commun., 6, 6591, doi:10.1038/ncomms7591.

428 Martinez-Sanchez, J.N., and T. Cavazos, 2014: Eastern Tropical Pacific hurricane

429 variability and landfalls on Mexican coasts. Climate Research, 58(3), pp.221-234. 
430 McDonald, J.H., 2014: Handbook of Biological Statistics (3rd ed.). Sparky House

431 Publishing, Baltimore, Maryland.

432 Mei, W., S. P. Xie, F. Primeau, J. C. McWilliams, and C. Pasquero, 2015: Northwestern

433 Pacific typhoon intensity controlled by changes in ocean temperatures. Science advances, 434 1(4), p.e1500014.

435 Merrill, R. T., 1984: A comparison of large and small tropical cyclones. Mon. Wea.

436 Rev., 112, 1408-1418.

437 Rotunno, R., and K. A. Emanuel, 1987: An air-sea interaction theory for tropical

438 cyclones. Part II: Evolutionary study using a nonhydrostatic axisymmetric numerical

439 model.J.Atmos.Sci.,44, 542- 561, doi:10.1175/1520

$440 \quad$ 0469(1987)044,0542:AAITFT.2.0.CO;2.

441 Shen, W., 2006: Does the size of hurricane eye matter with its intensity?, Geophys. Res.

442 Lett., 33, L18813, doi:10.1029/2006GL027313.

443 Smith, T. M., R. W. Reynolds, T. C. Peterson, and J. Lawrimore, 2008: Improvements to

444 NOAA's historical merged land-ocean surface temperature analysis (1880-2006). J Clim $445 \quad 21: 2283-2296$.

446 Stern, D. P., J. L. Vigh, D. S. Nolan, and F. Zhang, 2015: Revisiting the relationship

447 between eyewall contraction and intensification. Journal of the Atmospheric Sciences, 448 72(4), pp.1283-1306.

449 Takagi, H., and W. Wu, 2016: Maximum wind radius estimated by the $50 \mathrm{kt}$ radius:

450 improvement of storm surge forecasting over the western North Pacific. Nat. Hazards

451 Earth Syst. Sci ., 16, 705-717. 
452 Webster, P. J., G. J. Holland, J. A. Curry, and H.-R. Chang, 2005: Changes in tropical

453 cyclone number, duration, and intensity in a warming environment. Science 309, 1844-

4541846.

455 Xu, J., Y. Wang, and Z. M. Tan, 2016: The Relationship between Sea Surface

456 Temperature and Maximum Intensification Rate of Tropical Cyclones in the North

457 Atlantic. Journal of the Atmospheric Sciences, 73(12), pp.4979-4988.

458 


\section{List of Figures}

460 FIG. 1. 2001-2016 time series of the radius of maximum wind, the average radius of $34 \mathrm{kt}$

461 wind, and storm days for 3 basins combined. The blue, red, and green solid curves are for

462 TS, HT, and ALL storms, respectively. Dotted and dashed lines respectively show the

463 best fit linear and quadratic trends. The linear trend values are shown in the top of each

464 panel.

465

466 FIG. 2. 2001-2016 time series of storm days for the (a) NATL, (b) WPAC and (c) EPAC

467 individually. The blue, red, and green solid curves are for TS, HT, and ALL storms,

468 respectively. Dotted and dashed lines respectively show the best-fit linear and quadratic

469 trends. The linear trend values are shown in the top of each panel.

470

471 FIG 3. 2001-2016 time series of the radius of maximum wind for the (a) NATL, (b)

472 WPAC, and (c) EPAC. The blue, red, and green solid curves are for TS, HT, and ALL

473 storms, respectively. Dotted and dashed lines respectively show the best-fit linear and

474 quadratic trends. The linear trend values are shown in the top of each panel.

475

476 FIG 4. 2001-2016 time series of the average radius of 34-kt wind for the (a) NATL, (b)

477 WPAC, and (c) EPAC. The blue, red, and green solid curves are for TS, HT, and ALL

478 storms, respectively. Dotted and dashed lines show the best-fit linear and quadratic

479 trends. The linear trend values are shown in the top of each panel. 
481 FIG. 5. 1988-2015 time series of the radius of maximum wind, the average radius of 34-kt

482 wind, and storm days for the NATL, derived from extended best track data. The blue, red, 483 and green solid curves are for TS, HT, and ALL storms, respectively. Dotted and dashed

484 lines show the best fit linear and quadratic trends. The linear trend values are shown at 485 the top of each panel.

486

487 FIG. 6. 1977-2015 time series of the average radius of 50-kt wind, the average radius of 488 30-kt wind, and storm days for the WPAC, derived from extended best track data. The 489 blue, red, and green solid curves are for TS, HT, and ALL storms, respectively. Dotted 490 and dashed lines show the best-fit linear and quadratic trends. The linear trend values are 491 shown at the top of each panel.

492

493 FIG. 7. The difference of 2012-2015 SST 5-year mean and 2001-2005 SST 5 year mean. 494 495 
496 TABLE 1. P-values for Linear Fittings of RMW, AR34, and SD time series for TS, HT,

497 and ALL storms for the combined in the NATL, WPAC, and EPAC basins from 2001-

498 2016. Bold red denotes significance levels of at least $90 \%$.

499

\begin{tabular}{|c|c|c|c|}
\hline \multirow{2}{*}{} & \multicolumn{3}{|c|}{ Combined 3 basins } \\
\cline { 2 - 4 } & TS & HT & ALL \\
\hline RMW & 0.0085 & 0.2809 & 0.0743 \\
\hline AR34 & 0.9155 & 0.0043 & 0.0545 \\
\hline SD & 0.2715 & 0.4332 & 0.8729 \\
\hline
\end{tabular}

500

501 TABLE 2. P-values for Linear Fittings of RMW, AR34, and SD time series for TS, HT,

502 and ALL storms in the NATL, WPAC, and EPAC basins from 2001-2016. Bold red

503 denotes significance levels of at least $90 \%$.

504

\begin{tabular}{|c|c|c|c|c|c|c|c|c|c|}
\hline \multirow{2}{*}{} & \multicolumn{3}{|c|}{ NATL } & \multicolumn{3}{c|}{ WPAC } & \multicolumn{3}{c|}{ EPAC } \\
\cline { 2 - 10 } & TS & HT & ALL & TS & HT & ALL & TS & HT & ALL \\
\hline RMW & $\mathbf{0 . 0 0 0 2}$ & 0.3186 & 0.0041 & 0.1055 & 0.1539 & 0.2934 & 0.6897 & 0.0341 & 0.7621 \\
\hline AR34 & 0.6437 & 0.3556 & 0.8532 & 0.7822 & 0.4470 & 0.4355 & 0.1686 & 0.0369 & 0.1426 \\
\hline SD & 0.7601 & 0.2372 & 0.4677 & 0.6772 & 0.1321 & 0.4323 & 0.0096 & 0.0100 & 0.0046 \\
\hline
\end{tabular}

505

506

507

508

509

510 
512 TABLE 3. P-values for Quadratic Fittings of RMW, AR34, and SD time series for TS, HT,

513 and ALL storms in the NATL, WPAC, and EPAC basins from 2001-2016. Bold red

514 denotes significance levels of at least $90 \%$.

\begin{tabular}{|c|c|c|c|c|c|c|c|c|c|}
\hline \multirow{2}{*}{} & \multicolumn{3}{|c|}{ NATL } & \multicolumn{3}{c|}{ WPAC } & \multicolumn{3}{c|}{ EPAC } \\
\cline { 2 - 9 } & TS & HT & ALL & TS & HT & ALL & TS & HT & ALL \\
\hline RMW & 0.0018 & 0.3186 & $\mathbf{0 . 0 0 4 1}$ & $\mathbf{0 . 0 0 0 3}$ & $\mathbf{0 . 0 9 3 0}$ & $\mathbf{0 . 0 2 0 6}$ & $\mathbf{0 . 0 6 5 6}$ & $\mathbf{0 . 0 0 0 3}$ & $\mathbf{0 . 0 7 1 9}$ \\
\hline AR34 & 0.5298 & 0.2653 & 0.5015 & 0.1075 & $\mathbf{0 . 0 4 7 4}$ & $\mathbf{0 . 0 1 5 7}$ & $\mathbf{0 . 0 0 0 0}$ & $\mathbf{0 . 0 0 1 4}$ & $\mathbf{0 . 0 0 0 7}$ \\
\hline SD & 0.4188 & 0.1611 & 0.2767 & 0.4015 & $\mathbf{0 . 0 1 4 7}$ & $\mathbf{0 . 0 9 3 8}$ & $\mathbf{0 . 0 0 0 3}$ & $\mathbf{0 . 0 0 1 0}$ & $\mathbf{0 . 0 0 0 1}$ \\
\hline
\end{tabular}

515

516 TABLE 4. P-values for Linear Fittings of RMW, AR34, and SD time series for TS, HT,

517 and ALL storms for the NATL basin from 1988-2016. Bold red denotes significance

518 levels of at least $90 \%$.

\begin{tabular}{|c|c|c|c|}
\hline \multirow{2}{*}{} & \multicolumn{3}{|c|}{ NATL } \\
\cline { 2 - 4 } & TS & HT & ALL \\
\hline RMW & $\mathbf{0 . 0 0 0 2}$ & $\mathbf{0 . 0 1 7 2}$ & $\mathbf{0 . 0 0 1 1}$ \\
\hline AR34 & $\mathbf{0 . 0 0 4 0}$ & 0.7103 & 0.2595 \\
\hline SD & $\mathbf{0 . 0 1 5 8}$ & 0.8774 & 0.1711 \\
\hline
\end{tabular}

519

520 TABLE 5. P-values for Quadratic Fittings of RMW, AR34, and SD time series for TS, HT,

521 and ALL storms for the NATL basin from1988-2016. Bold red denotes significance

522 levels of at least $90 \%$.

523

\begin{tabular}{|c|c|c|c|}
\hline \multirow{2}{*}{} & \multicolumn{3}{|c|}{ NATL } \\
\cline { 2 - 4 } & TS & HT & ALL \\
\hline RMW & $\mathbf{0 . 0 0 0 0}$ & $\mathbf{0 . 0 1 1 5}$ & $\mathbf{0 . 0 0 0 0}$ \\
\hline AR34 & $\mathbf{0 . 0 0 2 5}$ & 0.5034 & 0.1581 \\
\hline SD & $\mathbf{0 . 0 0 4 7}$ & $\mathbf{0 . 0 6 5 5}$ & $\mathbf{0 . 0 2 7 1}$ \\
\hline
\end{tabular}


525 TABLE 6. P-values for Linear Fittings of AR50, AR30, and SD time series for TS, HT,

526 and ALL storms for the WPAC basin, based on 1977-2016 JMA data. Bold red denotes

527 significance levels of at least $90 \%$.

528

530

\begin{tabular}{|c|c|c|c|}
\hline \multirow{2}{*}{} & \multicolumn{3}{|l|}{ WPAC 1977-2016 JMA data } \\
\cline { 2 - 4 } & TS & HT & ALL \\
\hline AR50 & na & $\mathbf{0 . 0 0 0 3}$ & na \\
\hline AR30 & 0.2359 & $\mathbf{0 . 0 7 5 0}$ & 0.8646 \\
\hline SD & 0.2295 & 0.4090 & 0.8735 \\
\hline
\end{tabular}

531 TABLE 7. P-values for Quadratic Fittings of AR50, AR30, and SD time series for TS,

532 HT, and ALL storms for the WPAC basin, based on 1977-2016 JMA data. Bold red

533 denotes significance levels of at least $90 \%$.

534

\begin{tabular}{|c|c|c|r|}
\hline \multirow{2}{*}{} & \multicolumn{3}{|l|}{ WPAC 1977-2016 JMA data 535 } \\
\cline { 2 - 4 } & TS & HT & ALL $_{537}^{536}$ \\
\hline AR50 & na & 0.0001 & na 538 \\
\hline AR30 & 0.1288 & 0.0000 & 0.003739 \\
\hline SD & 0.0958 & 0.1689 & 0.202541 \\
\hline
\end{tabular}

543 TABLE 8. Correlation between SSTA/SSTD and RMW, AR34, and SD time series for TS,

544 HT, and ALL storms in the combined NATL, WPAC, and EPAC basins (2001-2016).

545 Bold red denotes significance levels of at least $90 \%$.

\begin{tabular}{|c|c|c|c|l|l|l|}
\hline \multirow{2}{*}{} & \multicolumn{3}{|c|}{ SSTA } & \multicolumn{3}{c|}{ SSTD } \\
\cline { 2 - 7 } & TS & HT & ALL & TS & HT & ALL \\
\hline RMW & 0.2628 & 0.1306 & 0.1445 & 0.0559 & -0.2663 & 0.0019 \\
\hline AR34 & 0.1361 & -0.0206 & 0.2535 & 0.1091 & -0.1566 & 0.0225 \\
\hline SD & 0.1949 & 0.0429 & 0.0784 & $\mathbf{0 . 2 4 6 9}$ & -0.0482 & 0.1557 \\
\hline
\end{tabular}


548 TABLE 9. Correlations between SSTA and RMW, AR34, and SD time series for TS, HT,

549 and ALL storms in the NATL, WPAC, and EPAC basins individually. Bold red denotes

550 significance levels of at least $90 \%$.

\begin{tabular}{|c|c|c|c|c|c|c|c|c|c|}
\hline \multirow{2}{*}{} & \multicolumn{3}{|c|}{ NATL } & \multicolumn{3}{c|}{ WPAC } & \multicolumn{3}{c|}{ EPAC } \\
\cline { 2 - 9 } & TS & HT & ALL & TS & HT & ALL & TS & HT & ALL \\
\hline RMW & 0.1238 & 0.2983 & 0.1417 & 0.3363 & -0.0833 & 0.2061 & 0.3912 & 0.1292 & 0.3089 \\
\hline AR34 & 0.0364 & 0.0836 & -0.0083 & -0.2543 & -0.2105 & -0.2133 & 0.5059 & 0.2220 & 0.3770 \\
\hline SD & -0.0488 & -0.6221 & -0.3068 & -0.4959 & -0.2742 & -0.4523 & 0.6714 & 0.6523 & 0.7136 \\
\hline
\end{tabular}

551

552 TABLE 10. Correlations between SSTD and RMW, AR34, and SD time series (2001-

553 2016) for TS, HT, and ALL storms in the NATL, WPAC, and EPAC basins. Bold red

554 denotes significance levels of at least $90 \%$.

\begin{tabular}{|c|c|c|c|c|c|c|c|c|c|}
\hline \multirow{2}{*}{} & \multicolumn{3}{|c|}{ NATL } & \multicolumn{3}{c|}{ WPAC } & \multicolumn{3}{c|}{ EPAC } \\
\cline { 2 - 9 } & TS & HT & ALL & TS & HT & ALL & TS & HT & ALL \\
\hline RMW & -0.4180 & $\mathbf{0 . 4 7 9 7}$ & -0.2431 & 0.0593 & $\mathbf{0 . 5 6 1 7}$ & 0.3012 & -0.4164 & -0.0329 & -0.1965 \\
\hline AR34 & 0.1603 & 0.3483 & 0.3126 & -0.1177 & 0.1853 & -0.0057 & -0.5952 & -0.0124 & -0.3428 \\
\hline SD & -0.3159 & -0.3953 & -0.2501 & -0.6540 & -0.2693 & -0.5538 & -0.4460 & -0.0390 & -0.4316 \\
\hline
\end{tabular}

555

556 TABLE 11. Correlations between SSTA/SSTD and RMW, AR34, and SD in the 1988-

5572016 NATL time series for TS, HT, and ALL storms. Bold red denotes significance

558 levels of at least $90 \%$.

\begin{tabular}{|c|c|c|c|c|c|c|}
\hline \multirow{2}{*}{} & \multicolumn{3}{|c|}{ SSTA } & \multicolumn{3}{c|}{ SSTD } \\
\cline { 2 - 7 } & TS & HT & ALL & TS & HT & ALL \\
\hline RMW & 0.0559 & -0.2663 & 0.0019 & -0.0274 & -0.1159 & 0.2425 \\
\hline AR34 & 0.1091 & -0.1566 & 0.0225 & 0.4032 & -0.0894 & -0.0165 \\
\hline SD & 0.5570 & 0.4195 & 0.1344 & 0.2114 & 0.1829 & 0.0055 \\
\hline
\end{tabular}

559 
560 TABLE 12. Correlation between SSTA/SSTD and RMW, AR34, and SD for TS, HT, and

561 ALL storms for the WPAC basin, based on 1977-2016 JMA data. Bold red denotes

562 significance levels of at least $90 \%$.

563

\begin{tabular}{|c|c|c|c|l|l|l|}
\hline & \multicolumn{3}{|c|}{ SSTA } & \multicolumn{3}{c|}{ SSTD } \\
\cline { 2 - 7 } & TS & HT & ALL & TS & HT & ALL \\
\hline AR30 & -0.2006 & -0.1247 & -0.2381 & -0.3572 & -0.1938 & -0.4845 \\
\hline SD & -0.1678 & -0.1243 & -0.2241 & -0.1918 & -0.3029 & -0.3623 \\
\hline
\end{tabular}

564

565 

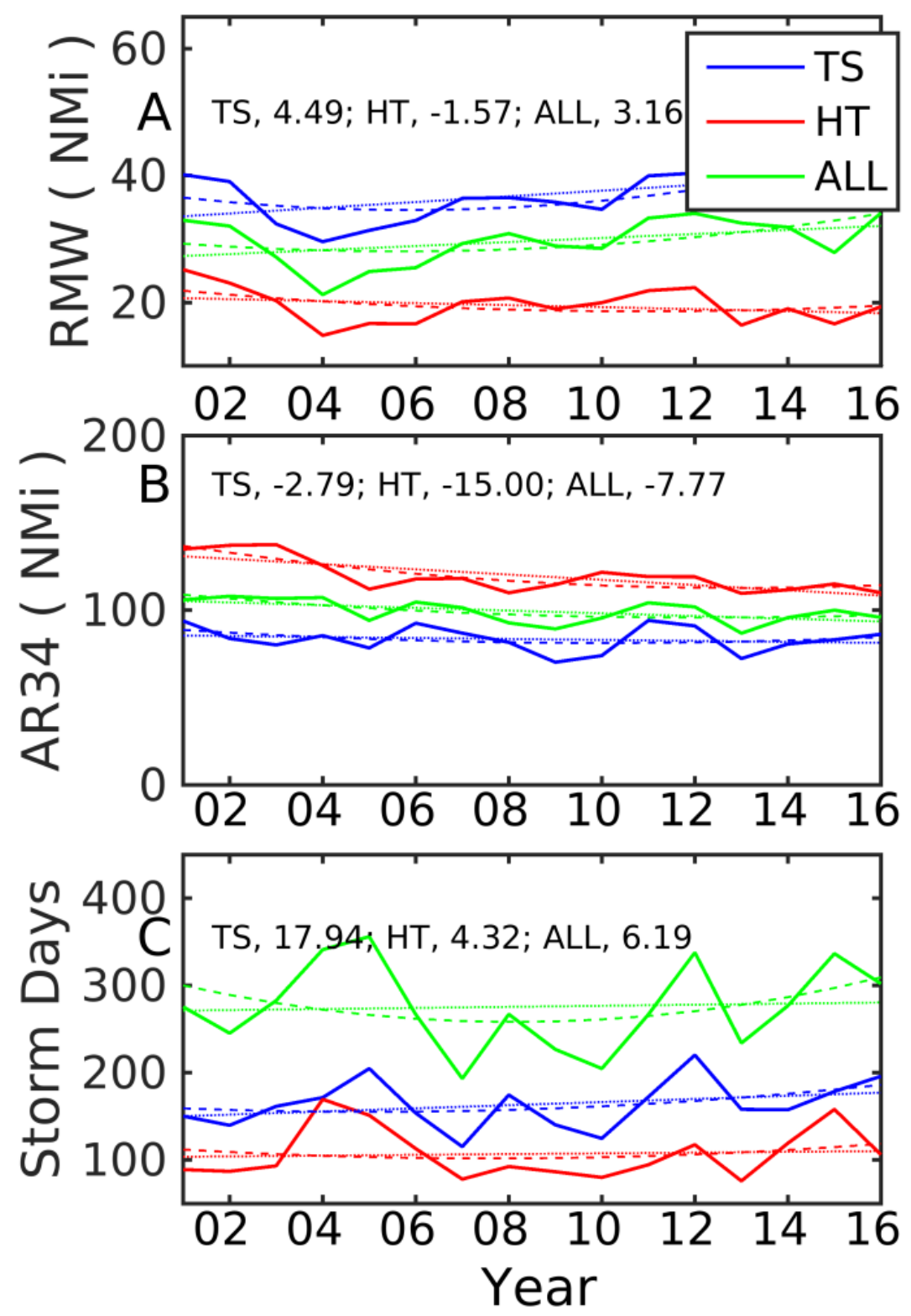

566

567

568

569

570

571

572
FIG. 1. 2001-2016 time series of the radius of maximum wind, the average radius of 34 kt wind, and storm days for 3 basins combined. The blue, red, and green solid curves are for TS, HT, and ALL storms, respectively. Dotted and dashed lines respectively show the best fit linear and quadratic trends. The linear trend values are shown in the top of each panel 

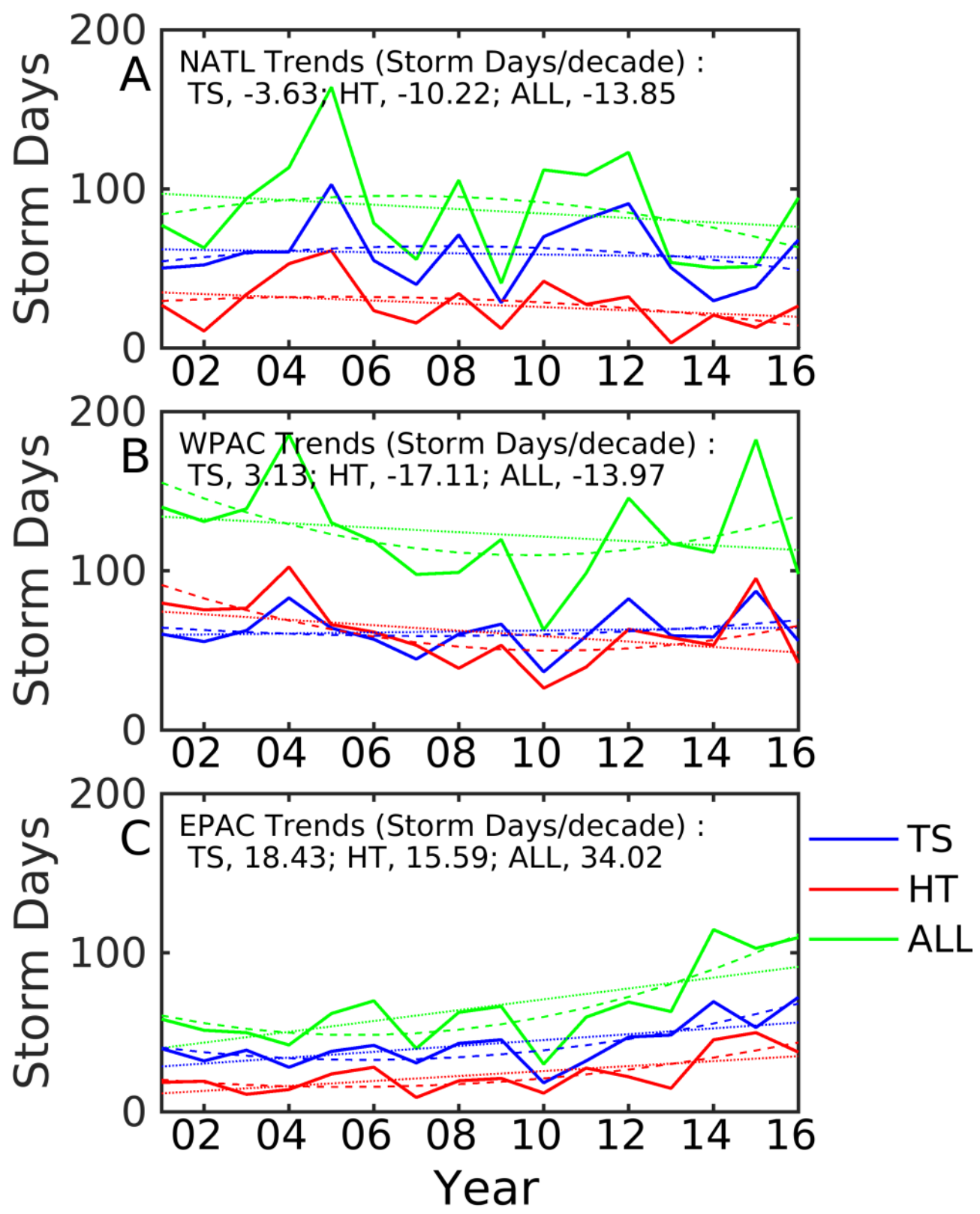

574 FIG. 2. 2001-2016 time series of storm days for the (a) NATL, (b) WPAC and (c) EPAC 575 individually. The blue, red, and green solid curves are for TS, HT, and ALL storms, 576 respectively. Dotted and dashed lines respectively show the best-fit linear and quadratic 577 trends. The linear trend values are shown in the top of each panel. 


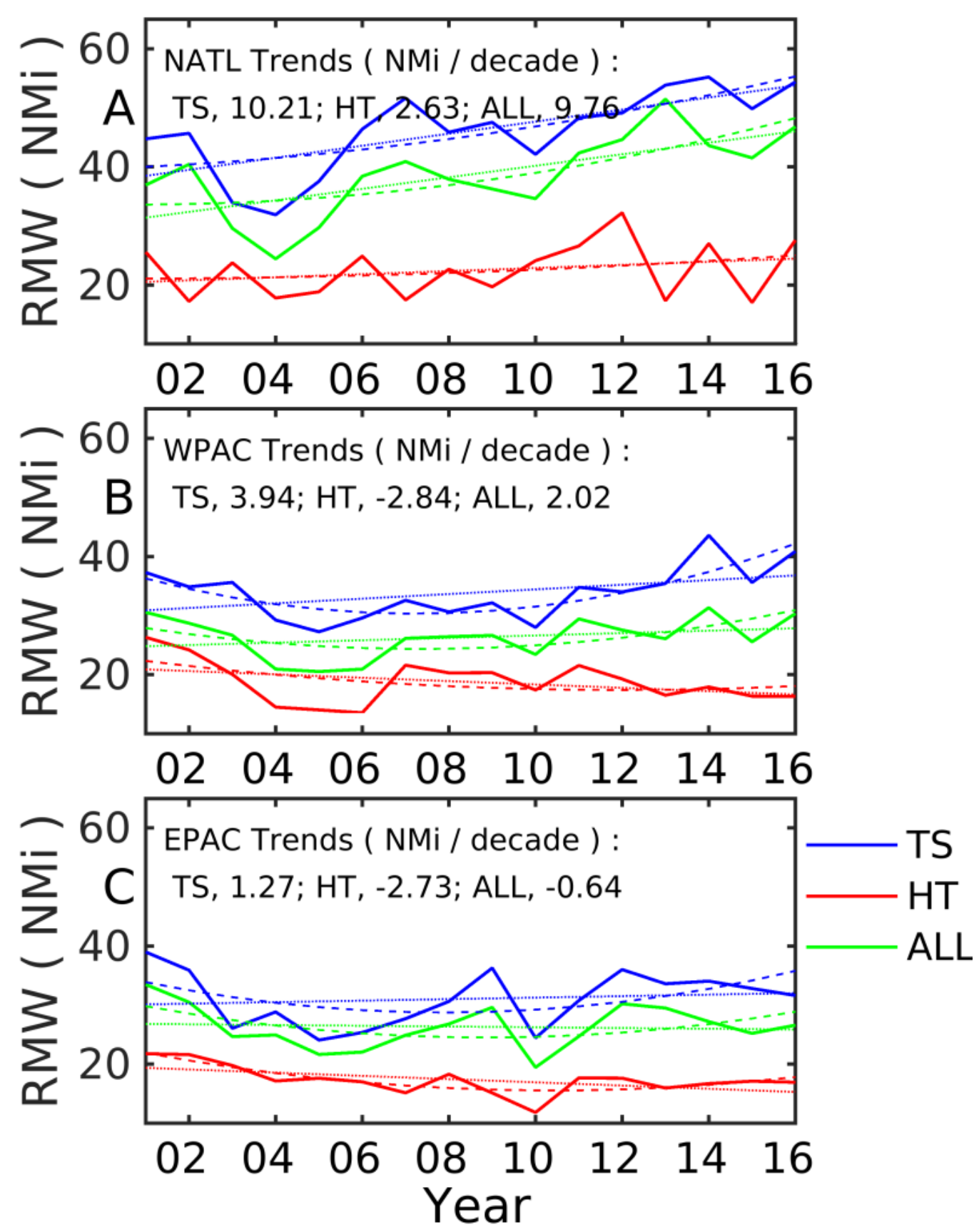

580 FIG. 3. 2001-2016 time series of the radius of maximum wind for the (a) NATL, (b) 581 WPAC, and (c) EPAC. The blue, red, and green solid curves are for TS, HT, and ALL 582 storms, respectively. Dotted and dashed lines respectively show the best-fit linear and 583 quadratic trends. The linear trend values are shown in the top of each panel. 

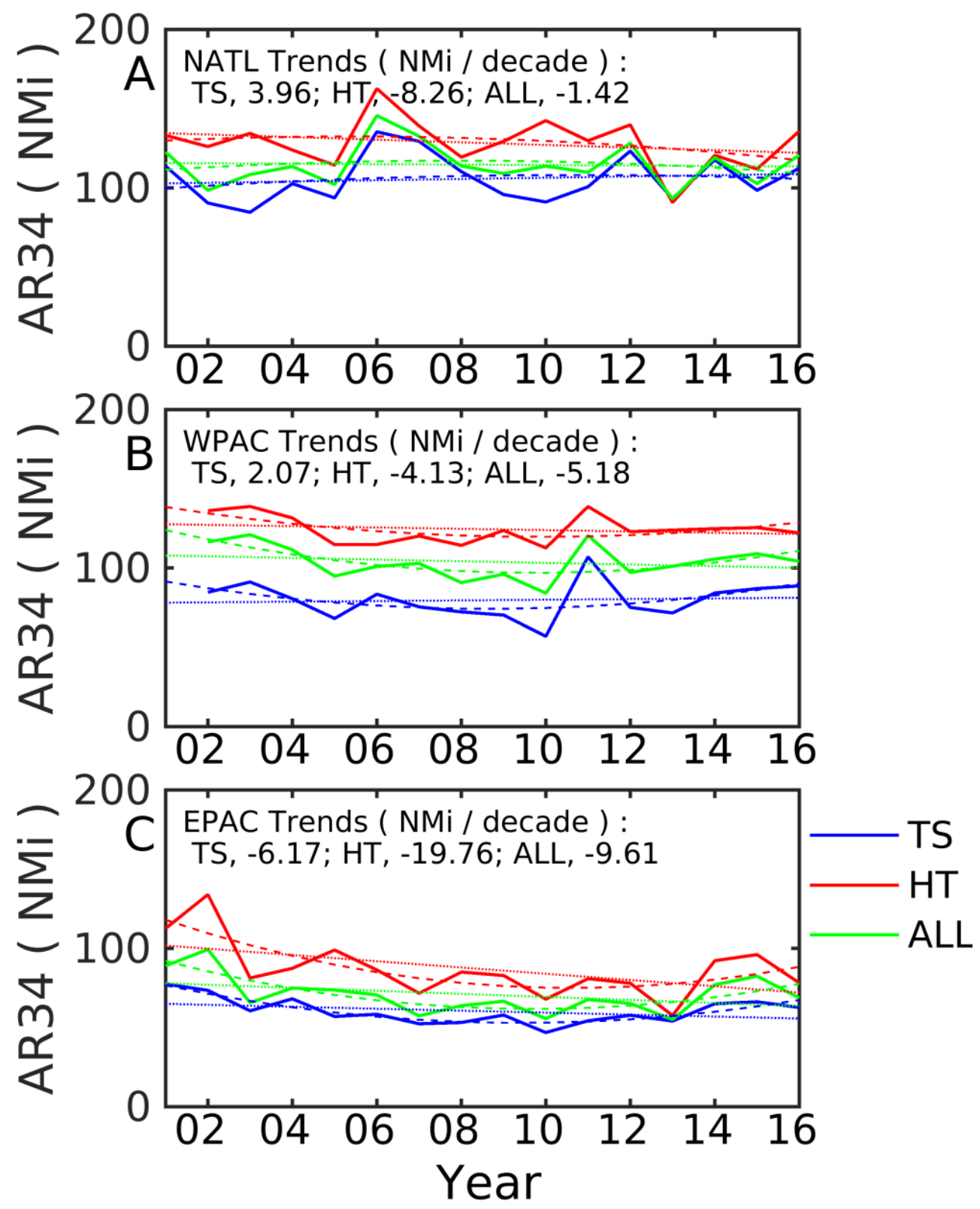

FIG. 4. -2016 time series of the average radius of 34-kt wind for the (a) NATL, (b) WPAC, and (c) EPAC. The blue, red, and green solid curves are for TS, HT, and ALL storms, respectively. Dotted and dashed lines show the best-fit linear and quadratic 


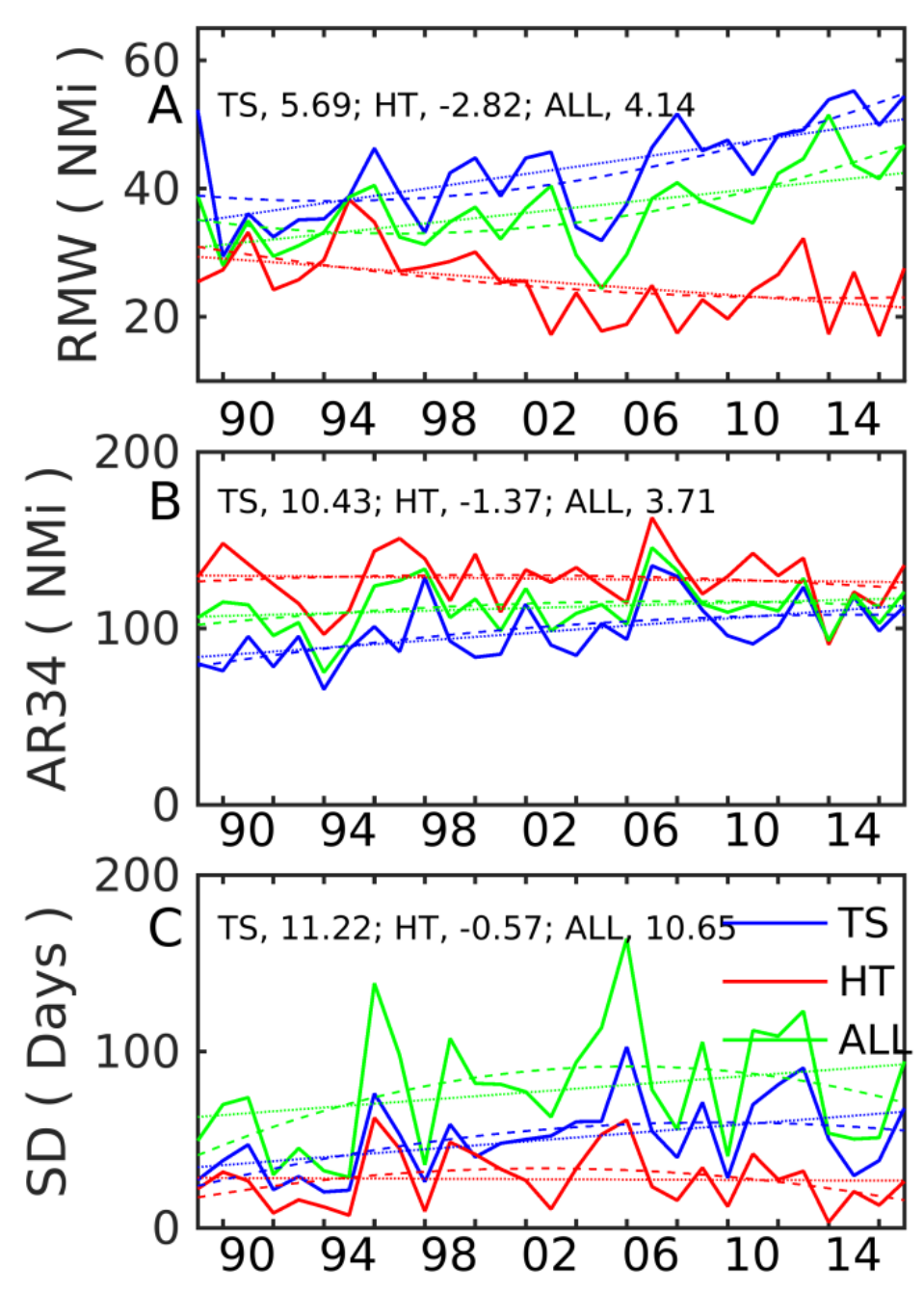

594

595

596

597

598

599

600

601

602
FIG. 5. 1988-2015 time series of the radius of maximum wind, the average radius of 34-kt wind, and storm days for the NATL, derived from extended best track data. The blue, red, and green solid curves are for TS, HT, and ALL storms, respectively. Dotted and dashed lines show the best fit linear and quadratic trends. The linear trend values are shown at the top of each panel. 

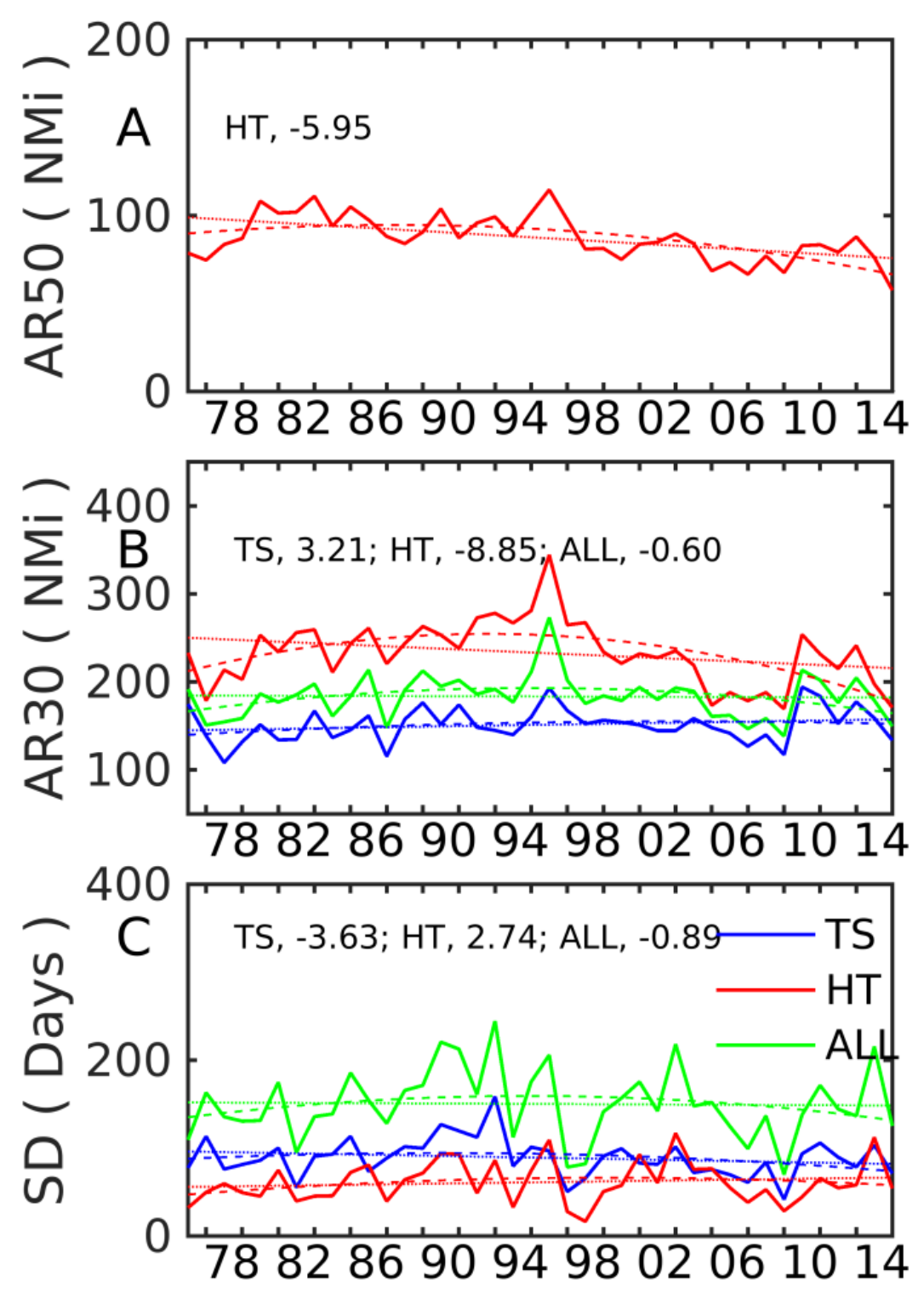

603

604

605

606

607

608

609

610

611

612
FIG. 6. 1977-2015 time series of the average radius of 50-kt wind, the average radius of 30-kt wind, and storm days for the WPAC, derived from extended best track data. The blue, red, and green solid curves are for TS, HT, and ALL storms, respectively. Dotted and dashed lines show the best-fit linear and quadratic trends. The linear trend values are shown at the top of each panel. 

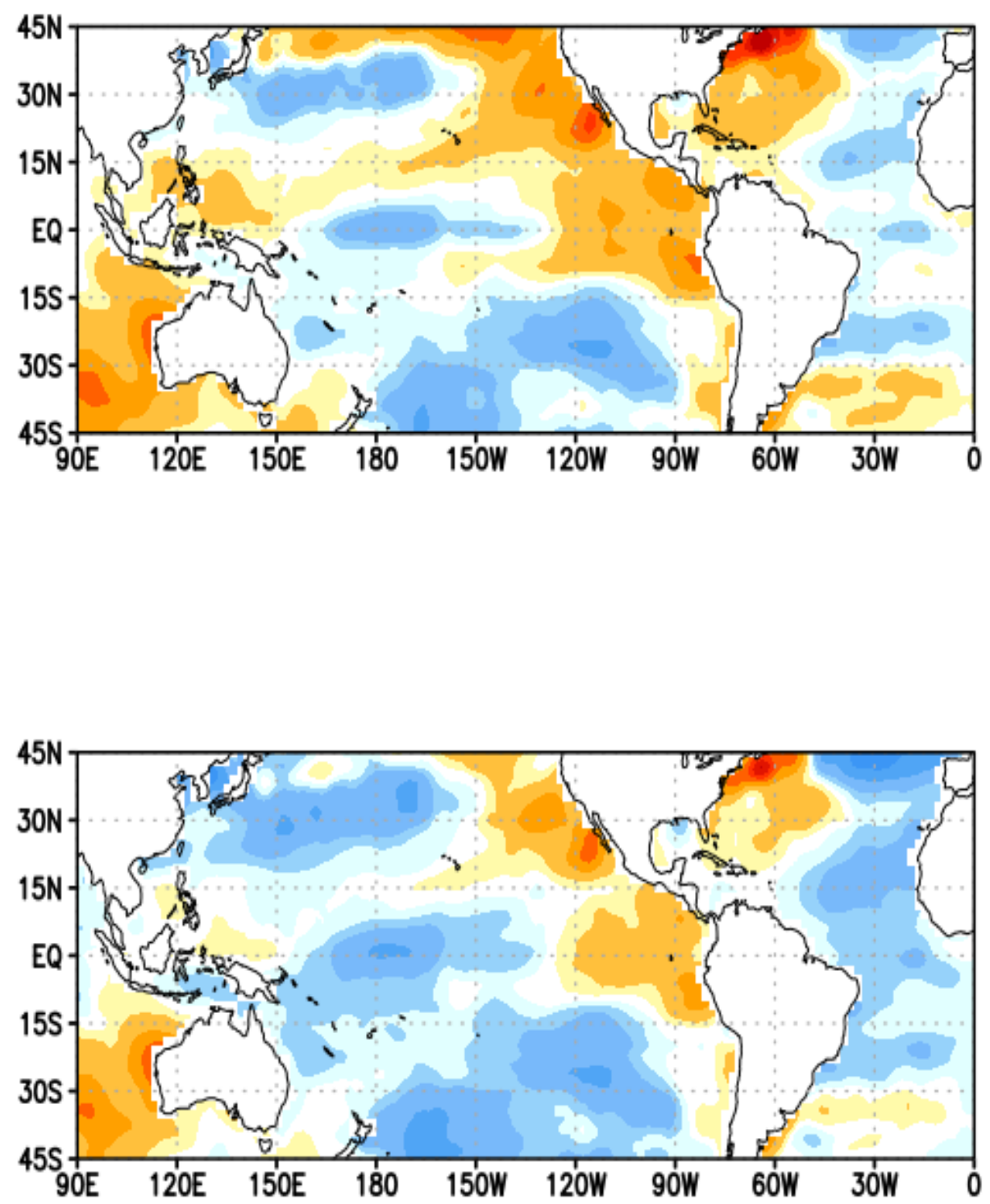

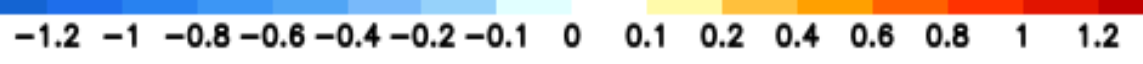

614

615 FIG. 7. The difference of 2012-2015 SST 5-year mean and 2001-2005 SST 5 year mean.

616 